\title{
Redes e configurações de comunicação e in formação: construíndo um modelo interpretativo de análise para o estudo da questão do conhecimento na sociedade
}

\author{
Regina Maria Marteleto \\ Programa de Pós-Graduação em Ciência da Informação \\ $\mathrm{CNPq} / \mathrm{IBICT}$ - UFRJ/ECO \\ E-mail remartel@prolink.com.br
}

\begin{abstract}
RESUMEN
El artículo presenta un modelo interpretativo de análisis para estudiar el conocimiento, la comunicación y la información en las redes de movimientos sociales orientados por el paradigma de la educación popular en salud. El modelo parte de la espacialidad de las relaciones entre los agentes, tomando en cuenta el eslabón social y los modos de comunicación y transferencia de información que existe entre los individuos, grupos y entidades que integran y componen las redes. En otro plano estudia las redes de conocimiento y las textualidades que en las confrontaciones y alianzas se forman entre los lenguajes, los discursos y las cosmovisiones propias de los agentes internos y externos de los movimientos sociales. Se discuten los conceptos básicos que fundamentan el modelo y su operatividad metodológica.

Palabras Clave RedesSociales Informacón, MbimientoSodia; Conocimientoy Sociedad Comericaión Pedesde MbuimietosSodiales
\end{abstract}

Trabajo recibido el

21 de novienbre de 2000 类

Trabajo aceptado el 10 de enero de 2001

\section{COMMUNICATION AND INFORMATION NETWORKSAND CONFIGURATIONS: TOWARD BUILDING AN INTERPRETIVE-ANALYTICAL MODEL FOR THE STUDY OF KNOWLEDGE IN SOCIETY}

\section{REgINA MARIA MARTELETO}

\begin{abstract}
The article offers an interpretive model of analysis for the study of knowledge, communication and information within those social movement networks modeled after the popular health education paradigm. The model departs from the spatiality of the relationships between the agents, taking into account the social link and modalities of communication and information transference that exists between individual, groups and entities that constitu-
\end{abstract}

1 Este trabalho é parte dos resultados do Projeto Integrado de Pesquisa "Cultura, Espaço e Textualidade: relações inter-campos, redes sociais e novas configurações de comunicação e informação", financiado pelo CNPq, 1997-1999 
te networks. On another tack, the study examines networks of knowledge and the textures that are formed in the confrontations and alliances between languages, discourses and world-view of the internal and external agents of social movements. Basic concepts that lay the foundation of the model and its operative methodology are also discussed.

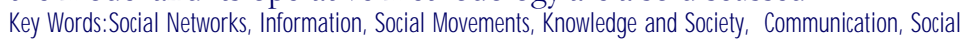
MbuerentsNetuarks

\section{Introdução}

modelo que se apresenta está baseado no pressuposto de que os movimentos sociais em geral, e aqueles que se orientam pelos princípios da educação popular em saúde, em particular, têm construído, ao longo da sua história de lutas e conquistas de melhores condições de vida e de saúde da população, formas próprias de conhecimento e transferência de informações, se comparadas àquelas vigentes nas esferas institucionais tradicionais da sociedade: universidades, órgãos públicos, empresas, o próprio Estado.

No quadro mais recente das chamadas sociedades da informação, da comunicação ou da aprendizagem, a questão do conhecimento, historicamente afeita aos atributos normativos e gerenciais do Estado patrimonialista, começa a ser objeto de práticas, políticas e arranjos locais, regionais e transnacionais, de forma mais independente da ação e regulação estatais. Essas transformações têm sua razão de ser fundada em três fatores principais.

Primeiro, na mudança do papel do próprio Estado, desde a retração de suas políticas sociais, nas quais estariam incluídas as políticas culturais, científicas e informacionais, até os compromissos globais com a modernização assumindo, ele também, o papel de gestor de políticas de reforma de suas próprias estruturas.

O segundo fator diz respeito a um certo deslocamento da questão do conhecimento e da informação das esferas acadêmicas e pedagógicas de regulação estatal que detinham o monopólio da sua expressão e disseminação social - para o ambiente das organizações empresas e seus novos paradigmas competitivos de gestão do conhecimento e inteligência empresarial. Novos modelos de competência cognitiva e informacional são desse modo formulados, alterando os padrões vigentes de aprendizagem, educação e trabalho.

Por último, na esfera da sociedade civil, uma pluralidade de iniciativas reunindo indivíduos, grupos e organizações com matizes políticos e ideológicos diversos e antagônicos - organizações sem fins lucrativos, movimentos sociais, grupos comunitários, entidades filantrópicas, igrejas, associações - conformam um espaço compósito e amalgamado que vem sendo nomeado como "Terceiro Setor". Nele se formam extensas redes de contato que mobilizam recursos materiais e simbólicos para 
a transformação social, promovendo novas e complementares formas de apropriação, produção, transferência e gestão de informações, fora da regulação estatal.

Esses fatores conjugados configuram o quadro conjuntural mais recente das políticas e arranjos institucionais nos três setores que compõem a estrutura social - o Estado, o mercado e a sociedade civil - no ambiente globalizado das chamadas sociedades da informação.

Sem perder de vista as variáveis macroestruturais apontadas, as questões que têm pautado nosso trabalho de pesquisa nos últimos anos situam-se nos ambientes locais de transferência e gestão informacional da sociedade civil renomeada - o Terceiro Setor- no âmbito das práticas e representações de educação popular em saúde.

Em trabalho de pesquisa anterior ${ }^{1} \mathrm{o}$ foco de análise foi dirigido para as ações político-pedagógicas de Organizações não-Governamentais de Assessoria e Apoio aos Movimentos Populares (ONGs/AMP), que têm ação direta e local junto à população. Formulou-se a hipótese de que tais organizações desempenham, dentre outros, o papel de mediadoras entre as esferas de produção do conhecimento e a sociedade, ao mobilizar as competências políticas e cognitivas dos seus especialistas nos projetos de assessoria aos movimentos populares e comunitários. Percebeu-se que nas suas atividades as ONGs desenvolvem formas de trato e transferência de informações e promovem elos de comunicação inovadores se comparados às práticas vigentes nos espaços institucionais tradicionais. Procuram ainda operar tanto a dimensão política quanto técnico- pedagógica do conhecimento, ou seja, seu potencial de produção de sentido e de instrumentalização informacional para a transformação social.

O convívio com essas questões em seu meio empírico de expressão levou à formulação da hipótese de que as configurações sociais que se formam pela ação em rede de diferentes indivíduos, grupos e organizações no Terceiro Setor -ou espacialidadetêm como correlato a formação de uma rede de sentidos -ou textualidade- tecida nas relações contraditórias entre diferentes formas de apropriação e expressão do conhecimento, da linguagem, da comunicação e da informação. A idéia de "terceiro conhecimento", construída no processo da pesquisa, evidencia as teias práticas e teóricas das redes de relações sociais e de construção de sentidos estudadas. O desdobramento da hipótese indica os arranjos e formas alternativos e inovadores de gestão dos conhecimentos e transferência da informação neste setor da sociedade.

A pesquisa vem sendo ambientada empiricamente em uma região periférica da cidade do Rio de Janeiro -os subúrbios da Leopoldin- composta por bairros de classe média baixa e grandes conjuntos de favelas, reunindo uma população de aproximadamente 600 mil pessoas. A área de favelas formou-se da remoção da população carente de áreas mais centrais da cidade, no quadro das políticas governamentais de urbanização dos anos 70. Grupos comunitários, associações e movimentos populares

1 Projeto Integrado de Pesquisa “Cultura, Informação e Sociedade - estudo de práticas informacionais em campos sociais específicos com vista à revisão e ampliação de modelos de comunicação e transferência da informação", 1994-96 
foram se organizando na região ao longo dos anos, com o objetivo de demandar melhorias para as suas precárias condições de saúde ambientais e sociais. Ao longo dos anos e de diferentes formas, tais grupos e entidades passaram a contar com o apoio de setores de duas instituições acadêmicas instaladas na região -a Escola Nacional de Saúde Pública (ENSP), unidade da Fundação Oswaldo Cruz (FIOCRUZ), e a Universidade Federal do Rio de Janeiro.

A interação entre especialistas do meio acadêmico ( alunos, professores, técnicos) e os grupos e lideranças populares se deu inicialmente por meio de demandas e intervenções no campo da saúde pública. Com o tempo formaram-se redes de contatos compostas por pessoas com diferentes posições no espaço social e, por conseqüência, detentoras de formas diferenciadas de conhecimento e inserção na sociedade. Os elos que estruturam as redes se fortalecem tendo em vista um objetivo comum - a luta pela melhoria das condições de vida da população da Leopoldina. Os conhecimentos e informações dos diferentes agentes (especialistas, lideranças, grupos e pessoas da comunidade, de setores dos serviços públicos) são recursos mobilizados de forma constante pelas redes de contatos, de forma a encaminhar ações e tomar decisões.

Alguns pressupostos gerais sustentam a prática de aproximação sucessiva desse universo rico de questões de conhecimento, comunicação, informação. O primeiro sugere que a informação não é uma entidade ou corpo fechado em si mesmo, ou ainda o simples registro de um evento, ação ou reflexão. De modo diferente, encontrase matéria informacional na imbricação dos atos, relações e representações dos agentes sociais. Como corolário, a busca de questões informacionais relevantes precisa levar em conta o modo como se organizam os grupos sociais e suas configurações individuais e coletivas.

Por isso nesse estudo adota-se uma leitura microscópica e reticular dos espaços sociais e simbólicos estudados, de modo a perceber o movimento da informação nas trocas comunicacionais e cognitivas entre os agentes que compõem as redes sociais.

Outro pressuposto orienta o modo de construção do objeto de estudo, que parte da exploração conceitual até a criação de modelos de análise em relação direta com as práticas dos agentes, em situações concretas e específicas.

Juntos esses pressupostos guiam os passos teóricos, metodológicos e operacionais de construção do modelo Interpretativo de Análise, desde a adaptação de conceitos e métodos das ciências sociais ao campo da pesquisa da informação, até a elaboração de parâmetros aplicativos de gestão do conhecimento. E assinalam o seu caráter interdisciplinar.

\section{A QUESTÃO DA INFORMAÇÃO NO TERCEIRO SETOR}

Conceito sociológico, de origem norte-americana, o "Terceiro Setor" é uma idéia polêmica e ainda em construção. Costuma vir referenciado pelas expressões 
“organizações sem fins lucrativos" ou "organizações voluntárias". É hoje um segmento da esfera pública não-estatal marcado pela lógica da sociedade civil, que se faz representar por uma variedade de atores sociais e formas de organização que experimentam modos de pensar e agir inovadores. ${ }^{1}$

A palavra-chave que sintoniza esse setor de contornos imprecisos é cidadania, entendida e praticada não apenas enquanto conquista de direitos universalmente definidos e outorgados, mas como definição das igualdades e diferenças plasmadas nas práticas e relações sociais: "o direito a ter direitos". ${ }^{2}$

As ações e iniciativas do "Terceiro Setor" possuem uma dimensão política, de transformação e revisão das relações entre o Estado e a sociedade, ${ }^{3}$ e ainda uma dimensão comunicacional e de apropriação do conhecimento produzido socialmente, com o desenvolvimento de estratégias de transferência e gestão informacional para a transformação e o desenvolvimento democrático da sociedade.

Este setor busca, estrategicamente, mecanismos de fortalecimento da participação popular junto às esferas governamentais, redimensionando as práticas políticas dos agentes internos e externos aos movimentos populares, agregando novos parâmetros de interlocução e participação popular na gestão pública, de produção de conhecimentos de forma compartilhada e de promoção de espaços de informação formais e informais.

Entende-se desse modo que o funcionamento do "Terceiro Setor" promove novas e complementares formas de institucionalização, transferência e gestão do conhecimento e das informações.

1 L. Landim comenta que "Terceiro Setor" ou "Setor sem fins lucrativos" ( do inglês "nonprofit sector") são termos que podem englobar os seguintes tipos de organizações: sociedades civis ou entidades sem fins lucrativos; associações; entidades filantrópicas, beneficentes ou de caridade; organizações não-governamentais (ONGs); fundações. Não são expressões consagradas no Brasil, quer pela literatura de caráter sociológico ou econômico, quer pela linguagem leiga, do senso comum. Uma marca comum das entidades assim englobadas é de que não fazem parte do Estado, nem a ele estão vinculadas, mas se revestem de caráter público na medida em que se dedicam a causas e problemas sociais. (Cf. Landim, L. L., 1993)

2 Dagnino, E., 1994, p.103-118

3 É necessário entender as novas relações entre a sociedade e o Estado a partir da "demissão" deste último em relação à primeira. A retração das políticas sociais do Estado traduz uma situação de "conversão" mundial ao neoliberalismo e suas políticas recessivas. Uma de suas piores conseqüências tem sido a demolição da idéia de serviço público, criando situações nos campos da educação, saúde, segurança pública - onde se exercem as funções ditas "sociais"- nas quais os funcionários ( professores, profissionais de serviços de saúde, magistrados subalternos, assistentes sociais, policiais) procuram compensar, sem dispor dos meios necessários, “...os efeitos e carências mais intoleráveis da lógica do mercado." ( Cf. P. Bourdieu, 1997, p. 215-227). E para a população desempregada e excluída do consumo coletivo de serviços estatais e de benesses do mercado, trata-se de criar novos elos e solidariedades que fortaleçam seus vínculos comunitários de pertencimento. A demissão ou retirada do Estado determina efeitos, às vezes inesperados, que podem ameaçar, com o tempo, o bom funcionamento das instituições democráticas. É nesse vácuo deixado pelo Estado que parecem agir as entidades, grupos e pessoas que atuam no chamado "Terceiro Setor", seja por atitudes caritativas, assistenciais ou mais propriamente políticas. 
Seu perfil encontra-se refletido nas tentativas de afirmação institucional de um conjunto de entidades que se auto-denominam "Organizações não-Governamentais" (ONGs). Estas organizam-se no espaço da sociedade civil, incorporando um objetivo maior de assessoria aos movimentos populares com mediações políticas, pedagógicas e informacionais. Tais intermediações traduzem as práticas que mobilizam recursos no "Terceiro Setor": solidariedade social, filantropia, voluntariado, reconhecimento e fortalecimento de quaisquer formas associativas, reinstitucionalização do âmbito público para aumento da igualdade, fortalecimento dos processos de informação pública para entendimento, controle e uso, pela população, dos serviços do Estado e criação de condições para uma "democracia cultural". ${ }^{1}$

Esta última - a democracia cultural - é de especial importância no contexto de uma "sociedade do conhecimento e da informação", no que tange ao reconhecimento da igualdade pelo respeito às diferenças e ao fortalecimento do poder dos setores populares para a criação de condições culturais de acesso e circulação dos bens simbólicos. Com os espaços públicos dominados hegemonicamente pelas classes superiores, a democratização cultural e, efetivamente, a inclusão de um novo projeto de cidadania serão consolidados na medida em que os novos cidadãos produzirem e fizerem circular sentidos e símbolos próprios dos setores populares nos circuitos e sistemas de comunicação e informação.

A promoção de espaços de interlocução entre diferentes esferas do conjunto social -o Estado, o mercado e a sociedade- relacionados aos valores da solidariedade, direito à igualdade e à diferença, cria situações de confronto simbólico, nas quais se afirmam as condições de construção da "democracia cultural" como possibilidade de expressão política ou imaginária de agentes diferencialmente posicionados no espaço social. Nesses foros comunicacionais de natureza pública fluem informações e constroem-se significados que levam a uma leitura das potencialidades gerenciais dos conhecimentos produzidos pelos coletivos sociais em sua conformação em redes, e não apenas enquanto agregados e estoques informacionais.

Nesse estudo o "Terceiro Setor" é entendido como uma vasta e indefinida teia formada pelos elos e contatos entre agentes situados em diferentes posições no espaço social, de acordo com sua inserção de classe e de pertencimento a determinados campos -o comunitário, o filantrópico, o político, o religioso, o pedagógico, o acadêmico, das ONGs. A diversidade de status social desses agentes tem como contraponto objetivos e interesses comuns de melhoria das condições de vida (meio ambiente) e de participação social e política (cidadania) da parcela da população não contemplada pelas políticas e serviços públicos, e sem acesso ao consumo. Do ponto de vista informacional, as teias sociais e estruturais dessas redes revelam as mediações cognitivas e comunicacionais presentes nas ações, representações e interações dos agentes.

1 Toro, J. B., 1997, p. 35-40 
De modo mais específico, o foco é dirigido para as ações e interações em rede de um conjunto de agentes que têm forte componente cognitivo, comunicacional e informacional, mesclando e confrontando discursos e cosmovisões próprios a cada um dos seus membros.

A pergunta inicial refere-se ao que acontece quando um grupo de pessoas e organizações são levadas a cooperar para encaminhar atividades as mais diversas -como produzir bens e serviços, dispensar conhecimentos e cuidados, participar da vida democrática ou ainda partilhar atividades de apoio social.

Paralelamente, pergunta-se sobre o movimento da informação e dos sentidos nas redes assim delineadas, sabendo que tanto as informações quanto os significados encontram-se relacionados à ação social, entendida como intervenção de transformação no dado da realidade vivida pela população. Ou ainda de apropriação e interpretação sucessivas dos sentidos oficias já atribuídos à realidade das coisas e das pessoas pela mídia, pelo Estado, pelo mercado.

Para perceber o movimento da informação como recurso simbólico -portanto prenhe de sentido cultural para os diferentes grupos e indivíduos- a cultura é aqui considerada como um "reservatório" ou "repertório" de práticas e referentes internos ou externos ao espaço social estudado que os agentes sociais mobilizam em função de tal ou qual conjuntura, mais do que normas e valores próprios aos grupos ou impondo-se mecanicamente a cada um dos seus membros. ${ }^{1}$

Por último uma premissa geral orienta os passos do estudo da informação no segmento do "Terceiro Setor" investigado - as redes de grupos, indivíduos e entidades atuantes nos subúrbios da Leopoldina, na cidade do Rio de Janeiro.

Os estudos da informação estão normalmente referenciados por uma lóġcaetática que localiza as questões informacionais nos "lugares de sígnos"2 onde são armazenados os "estoques de informação" "3gerenciados para responder as lacunas cognitivas de determinados perfis de receptores ou "usuários": pesquisadores, executivos, tecnólogos, especialistas.

1 Estamos nos aproximando da concepção de "inteligência coletiva" de Pierre Lévy, quando o autor afirma que "... Em um coletivo inteligente, a comunidade assume como objetivo a negociação permanente da ordem estabelecida, de sua linguagem, do papel de cada um, o discernimento e a definição de seus objetos, a reinterpretação de sua memória.... Portanto, longe de fundir as inteligências individuais em uma espécie de magma distinto, a inteligência coletiva é um processo de crescimento, de diferenciação e de retomada recíproca das singularidades." (Cf. Lévy, P. 1998, p. 28, grifos nossos)

2 A expressão "lugares de signos" ou "lugares fechados" é empregada por Bruno Latour ao se referir às bibliotecas e outros espaços de guarda e gestão dos produtos simbólicos. Para o autor esses lugares não guardam propriamente informações, pois estas, mais do que produtos, são relações que se estabelecem entre um centro (sujeito conhecedor) e uma periferia (objeto do conhecimento). No processo de desenvolvimento da forma informacional de conhecer, de entrar em contato com a realidade, muitas mediações se realizam, entre o centro e a periferia. É esse contexto ou teia informacional que deve ser levado em conta, quando se estudam os conhecimentos modernos: a biblioteca, os "lugares de signos", fazem parte de uma extensa rede na qual se fabricam os conhecimentos. (Cf. Latour, B. 1996, p.23-46; ver ainda Marteleto, R. 1996) 
De forma diferente, nos espaços informais ou menos institucionalizados que caracterizam o que se está designando por "Terceiro Setor" os processos de transferência da informação parecem se orientar por uma lóg்a dinâmica devido à informalidade das práticas e das interações, à diversidade dos perfis e papéis dos agentes envolvidos, à produção e uso das informações em função de determinadas ações pontuais.

Baseado nessa premissa geral, o resultado ou produto esperado da aplicação do modelo interpretativo construído não é a modelização de um "sistema de informação" pronto a atender, quando acionado, as necessidades de informação dos indivíduos, grupos ou entidades.

Espera-se mais indicar, com alguma segurança analítico-interpretativa, os caminhos e, talvez, os meios para o reconhecimento e o fortalecimento dos processos de gestão e das políticas do conhecimento nessa e em outras esferas do chamado Terceiro Setor da sociedade.

\section{O MODELO INTERPRETATIVO DE ANÁLISE}

\section{Princípios conceituais e metodológicos}

O modelo construído no processo da pesquisa teve por objetivo reunir um conjunto estruturado e coerente composto por conceitos e hipóteses operacionais, articulados entre si. É fruto e, ao mesmo tempo, baliza de orientação do processo de análise interpretativa que se realiza pelo confronto entre o quadro de referência teórico e metodológico inicial e os dados empíricos. ${ }^{1}$

3 Aldo Barreto emprega a idéia de "estoques de informação" para se referir ao que denominamos de ló ġaestática que orienta o modo de organizar e disseminar as informações pelos sistemas de informação convencionais, baseado mais na oferta do que na demanda informacional. (Cf. Barreto, A. 1994). Outros autores vêm empregando ou o mesmo termo ou termos diferentes para indicar a mesma idéia e colocar em questão a lógica da provisão informacional, centrada no emissor ou no mediador, no caso, os sistemas de informação.(Ver p. ex., Dervin, B. 1994; Paim, I., Nehmy, R. M. Q.,1998)

1 O modelo de análise é intepretativoporque intenta estudar fenômenos de informação como fenômenos sociais, com uma metodologia que os inscreve em estruturas locais de saber e de comunicação. Trata-se de uma tarefa de percepção de como as pessoas representam seus mundos, suas experiências, para então enxergar a relevância da informação, seja como sentido já dado, presente oficialmente nas estruturas sociais, seja como matéria simbólica que alimenta suas ações e seus sentidos de mundo. C. Geertz , na área da antropologia simbólica, fala de "entendimento do entendimento" (ou hermenêutica cultural) para indicar esse modo de percepção/representação da realidade do outro pelo pesquisador, chamando-o de "tradução" : oquenãosignifica simplesmentere moldarafoma queautraspesscastêmdeseexpressar entemosdasnossasfomas deexpressãa.., massimmostrar a lógica dasfomas deexpresãoddes, comnossa frasedogia. Una mtoddoga queseaproxima mais daquiloque umcúticofaz para tomar daroumpoema, dbqueoquefaz umastrônomoquandojustifica a existênia deuma es trda." (Cf. Geertz, C. 1997, p.20). Na análise do discurso trata-se de um "gesto de interpretação" que se dá porque o espaço simbólico é marcado pela incompletude : "A interpracacãoéovestígodoppos śvd. É olugar própriodaidedogjaeématerializada pda históia... Elasempresedádealgumlugardahistónae dasociedadeetemumadiręãa, queéoquedamamosdepdítica." (orlandi, Ep. 1996). De um ponto de vista epistemológico/metodológico, um modelo interpretativo de análise procura equilibrar o trabalho de análise - a operacionalização de conceitos analíticos e empíricos - "comaslentesdepecepcãopropardanadaspdasrepresentascõesdosagentesvistos, compersanalidadesúnicas, exemplares, indivíduostomadosemsua 
Para realizar a leitura interpretativa do conhecimento, sua emergência e relevância no cenário empírico estudado, o modelo foi construído e operacionalizado analiticamente empregando-se uma estrutura tridimensional- ou três planos de análise diferenciados e complementares entre si. De acordo com o foco da pesquisa, o conceito de reelefoi empregado como categoria ao mesmo tempo analítica (ou macro, ou sistêmica) e operacional (ou empírica) e constitui o marco teórico de referência principal do modelo de análise. (ver Figura 1)

O primeiro plano de leitura está relacionado aos elos, relações e interações entre os agentes, que são elementos básicos para a leitura da estrutura social empregando-se a idéia de rees Como complemento é empregado o conceito de campg de modo a situar os agentes componentes das redes estudadas em relação aos seus espaços institucionais de pertencimento. Este nível da análise é o das reess soiais decontatos

O segundo plano da análise interpretativa é o das reelesdeconheimetos. As redes estudadas são compostas por agentes que têm diferentes papéis, posições e inserções institucionais, unidos e orientados por objetivos comuns de mobilização de recursos para a mudança social. Os conhecimentos - o científico (ou lógico-racional) e o conhecimento de senso comum (ou prático) confrontam-se e se complementam nas situações práticas e discursivas do cotidiano, gerando espaços de funcionamento de "comunidades interpretativas". ${ }^{1}$ Nestas se promove o reconhecimento da existência de diferentes formas de saber e o confronto comunicativo entre elas. A idéia de "terceiro conhecimento", construída ao longo da pesquisa, funciona como operador empírico que permite visualizar situações práticas e discursivas de funcionamento das "comunidades interpretativas".

O terceiro plano é o das reelesdesentidosonde o foco da análise é dirigido para as representações e ações que os agentes elaboram e acionam em função de seus objetivos práticos. Entram em jogo os mitos, tradições, linguagens, sentimentos e percepções dos agentes vistos individualmente - suas subjetividades - e nas relações com os outros. Do ponto de vista metodológico são enfatizadas as suas diferentes linguagens: a narrativa, a científica, a política, a religiosa, nas situações práticas e discursivas do cotidiano vivido nos movimentos comunitários e populares. Neste plano são gerados os sentidos que realinham as representações e organizam as ações dos agentes.

O modelo interpretativo parte da @padalidadedas relações entre os agentes (ou estrutura social) de modo a situar cada sujeito em relação ao seu lugar e papel nas redes de contato. A arquitetura das redes é o plano básico da análise a partir do qual procu-

inteireza, inesosempeixões, interesses, pereppões, preenceitos, valures.." (Cf. Miceli, S. 1999, p.122, a comentar o procedimento analítico-interpretativo do sociólogo alemão N. Elias)

1 A idéia de commidadesintenpreativasé utilizada por B.S. Santos para indicar um dos caminhos de atuação de uma nova "universidade de idéias", que concorreria para a formulação de uma "nova epistemologia" integradora de diferentes formas de conhecimento. Segundo o autor, a "hegrmmia da universidadedexaniaderesidirnocaráterúnicoeexdusivodosaberqueproduz etransmite, para passara residirno caráter únicoeexdusivo da configuração desaberes quepropariona.". (Cf. Santos, B. S. 1995, p. 224) 
ra-se perceber e interpretar as textualidadesque se formam no encontro e confronto entre diferentes subjetividades e formas de conhecimento. Ou seja, os modos e situações de produção dos sentidos ou disputas simbólicas.

A operacionalização do modelo interpretativo de análise permite a reconstrução das redes dos movimentos sociais em sua materialidade prática e expressão simbólica. Essa dupla leitura das redes mostra os diferentes usos e fluxos das informações, as estratégias de comunicação e as formas alternativas de produção dos conhecimentos, o que aqui se denomina de configuraçães decammicaçãoeinformaçãa

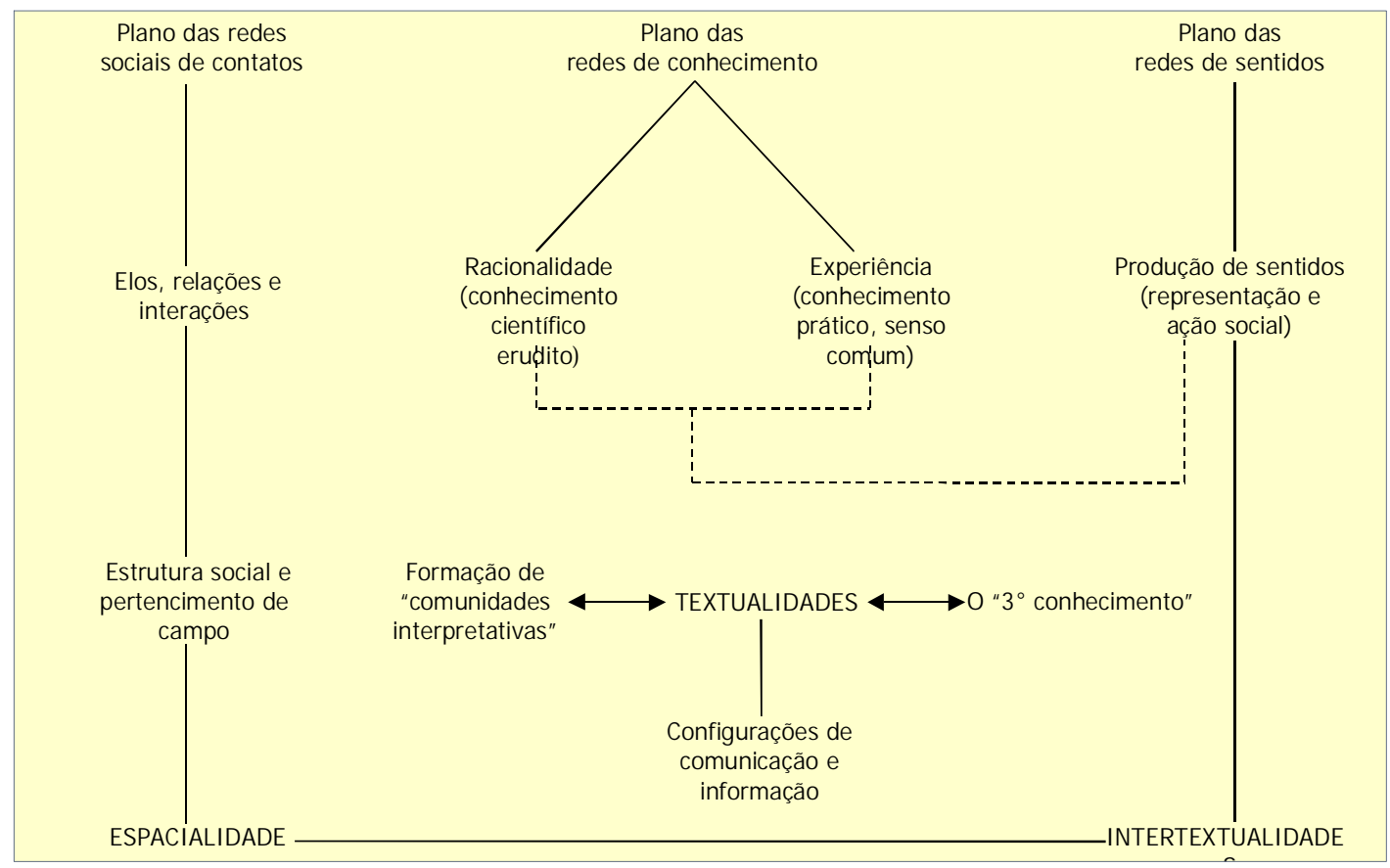

Fig 1 - Modelo Interpretativo de Análise

\section{Elementos teóricos}

\section{Reeles- pinápios grais}

Nas ciências sociais a idéia de rede é empregada para se referir à sociedade como um conjunto diverso de relações e funções que as pessoas desempenham umas em relação às outras. Como característica das sociedades complexas, cada associação de seres humanos funciona de maneira muito específica, o que cria uma dependência funcional entre os indivíduos. Estes vinculam-se ininterruptamente, formando longas cadeias de atos, estando sempre ligados a outros por laços invisíveis: relações de 
trabalho, propriedade, afeto e outros. Apesar de não serem vistos nem tocados, esse vínculos não são menos reais.

No espaço social, desde o momento em que nasce, o indivíduo passa a viver em uma rede de dependências que dificilmente consegue modificar ou romper. Apesar da aparente liberdade, existe uma gama de possibilidades restritas de funções e comportamentos possíveis para cada pessoa, condicionados pela sua posição social e o grupo a que pertence. São as relações sociais que vão moldando o indivíduo.

Para ter uma visão mais detalhada desse tipo de inter-relação, podemos pensar no objeto de que deriva o conceito de rede: a rede de tecido. Nessa rede, muitos fios isolados ligam-se uns aos outros. A rede só é compreensível em termos da maneira como eles se ligam, de sua relação recíproca. (...) Talvez ela atenda um pouco melhor a seu objetivo se imaginarmos a rede em constante movimento, num tecer e destecer ininterrupto de ligações. É assim que efetivamente cresce o indivíduo, partindo de uma rede de pessoas que existiam antes dele para uma rede que ele ajuda a formar.(...) É a ordem desse entrelaçamento incessante e sem começo que determina a forma e a natureza do ser humano individual. ${ }^{1}$

Essa representação das relações sociais permite perceber como uma rede de muitas unidades origina uma nova ordem que não pode ser entendida apenas por suas unidades individuais. Porém, no interior do todo, não deixa de ser uma ligação de fios individuais onde cada um constitui uma unidade em si, único em forma e posição.

A margem de decisão do indivíduo, no entanto, está sempre presa à distribuição de poder, à estrutura da dependência e das tensões no interior do grupo. Seja o que for decidido, isto o afastará de uns e o aliará a outros. A influência de uma pessoa sobre outras pode ser grande, mas a autonomia da rede em que ela atua é incomparavelmente mais forte.

Essa intedapendênaafunaional dos indivíduos indica um modo de entender o social levando-se em conta o indivíduo e suas interrelações tanto quanto a sociedade, ou conjunto mutante de indivíduos interrelacionados. O enfoque reticular das relações sociais chama a atenção para as interdependências humanas e os fatores que religam os indivíduos em configuraçães A idéia de rede e seus derivados não devem ser empregados como conceitos de substância, mas como conceitos relacionais. ${ }^{2}$

O conceito de reessé tributário de um conflito permanente entre diferentes correntes nas ciências sociais, que criam os pares dicotômicos indivíduo/sociedade; ator/estrutura; abordagens subjetivistas/objetivistas; enfoques micro ou macro da realidade social, colocando cada qual a ênfase analítica em uma das partes. Por exemplo, a antropologia estrutural entende as redes como descritivas, servindo para identificar o caráter perene das organizações e dos comportamentos sociais. Já a linha do individualismo metodológico desconstrói essa concepção privilegiando o ponto de vista do agente que produz sentido, e as relações sociais na formação do seu agir. As redes surgem como um novo instrumento face aos determinismos institucionais.

1 Elias, N., 1994, p.35 


\section{A análisederedes sociais}

Desde os estudos clássicos de redes sociais até os mais recentes, concorda-se que não existe uma "teoria de redes sociais", e que o conceito pode ser empregado com diversas teorias sociais, necessitando de dados empíricos complementares, além da identificação dos elos e relações entre indivíduos. ${ }^{1} \mathrm{~A}$ análise de redes pode ser aplicada ao estudo de diferentes situações e questões sociais.

O enfoque das redes estabelece um novo paradigma na pesquisa sobre a estrutura social. Para estudar como os comportamentos ou as opiniões dos indivíduos dependem das estruturas nas quais eles se inserem, a unidade de análise não são os atributos individuais (classe, sexo, idade, gênero) mas o conjunto de relações que os indivíduos estabelecem através das suas interações uns com os outros. A estrutura é apreendida concretamente como uma rede de relações e de limitações que pesa sobre as escolhas, as orientações, os comportamentos, as opiniões dos indivíduos.

2 Para desenvolver os conceitos de interdependência e configurações N. Elias recorre ao exemplo do jogo: "O termo configuração serve para criar uma ferramenta conceitual flexível, com a ajuda da qual pode-se desfazer a imposição social que nos obriga a pensar e a falar como se o"indivíduo" e a "sociedade" fossem figuras diferentes e até antagonistas. (...) Quatro homens sentados ao redor de uma mesa para jogar um jogo de cartas formam uma configuração. Seus atos são interdependentes. Neste caso igualmente, é o emprego do substantivo "jogo" que faz crer que o "jogo" possui uma existência própria. Pode-se dizer: "o jogo progride lentamente." Mas qual seja a objetividade dos termos empregados, é evidente que o desenvolvimento do jogo decorre das interpenetrações dos atos de um grupo de indivíduos interdependentes. Como demonstramos acima, o desenvolvimento da partida oferece uma autonomia relativa em relação a cada um dos jogadores, se esses últimos têm força relativamente igual. Mas ele não tem substância ou existência próprias, não é um ser independente dos jogadores, como o faz crer a formação da palavra "jogo". O jogo não é, por outro lado um "ideal tipo" a partir do qual um sociólogo pode retirar algumas generalidades, estudando o comportamento de cada um dos jogadores, para depois deduzir, de certas particularidades comuns a todos, as leis do comportamento individual. Nem o "jogo", nemos "jogadores', são abstrações. O mesmo pode ser dito da configuração que formam esses quatro jogadores ao redor da mesa. Se o termo " concreto" tem um sentido, pode-se dizer que a configuração que formam esses jogadores, e os próprios jogadores, são igualmente concretos. O que se deve entender por configuração, é a figura global sempre mutante que formam os jogadores; ela inclui não apenas seus intelectos, mas toda a sua pessoa, as ações e relações recíprocas. Como se pode ver, essa configuração forma um conjunto de tensões. A interdependência dos jogadores, condição necessária da existência de uma configuração específica, é uma interdependência enquanto aliados, mas também enquanto adversários." (Cf. Elias, N., 1991, p. 156-157; Heinich, N., 1997, p. 85-92)

1 Os antropólogos J. A. Barnes e E. Bott, autores clássicos e pioneiros dos estudos de redes sociais mostram que o conceito de redes pode ser empregado junto a diversos marcos conceituais. É mais um ferramental de análise do que propriamente um conceito analítico, ou construto teórico reconhecido. Ambos apontam para a necessidade de uma pesquisa de caráter etnográfico, para fazer funcionar o conceito. (Cf. Barnes, J. A.,1971; Bott, E., 1976). M. Emirbayer faz uma revisão de estudos de redes sociais ressaltando seus pressupostos teóricos. Apesar do crescimento dessa área de estudos, o autor afirma que ela não possui bases teóricas e críticas consistentes, sendo fortemente marcada pela empiria. Segundo o autor, a análise de redes sociais “... não é uma ”teoria" formal ou unitária que especifica leis, proposições ou correlações distintas, mas antes uma estratégia ampla para investigar a estrutura social." (Cf. Emirbayer, M., 1994, p. 1414) 
A análise de redes não constitui um fim em si mesma. Ela é o meio para realizar uma análise estrutural cujo objetivo é mostrar em que a forma da rede é explicativa dos fenômenos analisados. O objetivo é demonstrar que a análise de uma díade (interação entre duas pessoas) só tem sentido em relação ao conjunto das outras díades da rede, porque a sua posição estrutural tem necessariamente um efeito sobre sua forma, seu conteúdo e sua função. Portanto, a função de uma relação depende da posição estrutural dos elos, e o mesmo ocorre com o status e o papel de um ator. Uma rede não se reduz a uma simples soma de relações, e a sua forma exerce uma influência sobre cada relação. ${ }^{1}$

As redes nas ciências sociais designam normalmente - mas não exclusivamente os movimentos fracamente institucionalizados, reunindo indivíduos e grupos numa associação cujos termos são variáveis e sujeitos a uma reinterpretação em função dos limites que pesam sobre suas ações. É composta de indivíduos, grupos ou organizações e sua dinâmica está voltada para a perpetuação, a consolidação e o desenvolvimento das atividades dos seus membros.

Nos espaços informais as redes são iniciadas a partir da tomada de consciência de uma comunidade de interesses e/ou de valores entre seus participantes. Entre as motivações mais significativas para o desenvolvimento das redes estão os assuntos que relacionam os níveis de organização social - global, nacional, regional, estadual, local, comunitário. Independente das questões que se busca resolver, muitas vezes a participação em redes sociais envolve direitos, responsabilidades e vários níveis de tomada de decisões.

O estudo das redes coloca assim em evidência um dado da realidade social contemporânea que ainda vem sendo pouco explorado, ou seja, de que os indivíduos, dotados de recursos e capacidades propositivas organizam suas ações nos próprios espaços políticos em função de socializações e mobilizações suscitadas pelo próprio desenvolvimento das redes. Mesmo nascendo em uma esfera informal de relações sociais, os efeitos das redes podem ser percebidos fora de seu espaço, nas interações com o Estado, a sociedade ou outras instituições representativas.

De forma diferente das instituições, as redes não supõem necessariamente um centro hierárquico e uma organização vertical, sendo definidas pela multiplicidade quantitativa e qualitativa dos elos entre os seus diferentes membros, orientada por uma lógica associativa. Sua estrutura extensa e horizontal não exclui a existência de relações de poder e de dependência nas associações internas e nas relações com unidades externas. ${ }^{2}$

\section{Reeles dembimentossociais}

Os movimentos sociais em geral designam um tipo de ação coletiva orientada para a mudança, em que uma coletividade de pessoas é dirigida, de modo não-hie-

1 Degenne, A., Forsé, M., 1994, p. 7-12

2 Colonomos, A., 1995, p. 22-24 
rárquico, por um ator social. Os movimentos logram maior duração e integração e são eles em geral que originam as organizações, os partidos, as associações, a partir de uma consciência de grupo e das afinidades percebidas por indivíduos submetidos às mesmas pressões sociais ou que enfrentam idênticas dificuldades e obstáculos. ${ }^{1}$

Numerosos estudos, nas últimas décadas, têm mostrado as mudanças no perfil e na dinâmica dos movimentos sociais. A mudança básica estaria relacionada à alteração do seu foco mobilizador e reivindicatório da esfera da produção e do trabalho para as "condições de vida da população". Essa nova face dos movimentos os caracteriza como ações de exigência de atendimento de novas necessidades e, portanto, como lutas pela ampliação do acesso ao espaço político e aos benefícios do desenvolvimento econômico. ${ }^{2}$

Os novos movimentos sociais surgem como conseqüência das contradições geradas na desigualdade na propriedade, na apropriação do produto social e no planejamento produtivo. Embora sejam universais tais contradições, é a partir do seu contexto social específico que os movimentos as enfrentam e associam às carências básicas da população. Seu projeto fundamental é a construção da democracia em dupla perspectiva: institucional e das relações sociais ou "cultura democrática", a qual depende da capacidade de articulação de um espectro mais amplo de atores sociais e da reconstrução prática da cidadania. É um processo que aponta para a liberdade, para a igualdade, para a autonomia, para a autogestão, para o respeito à vida, para a representação política alternativa pelo próprio movimento, que são valores inerentes à cidadania e à sua conquista e exercício. ${ }^{3}$

Nos países pobres o atendimento da agenda de reivindicações dos novos movimentos sociais tem sido o mais forte elemento de construção democrática.

Nas análises mais recentes o enfoque das redes vem sendo empregado para a leitura mais abrangente dos elementos constitutivos dos movimentos, como o papel dos atores que os organizam e orientam; a coordenação social ou constituição dos movimentos e as dificuldades de organizar uma coletividade de pessoas de modo não-hierárquico; e o problema da estratégia política ou orientação para a mudança.

A reivindicação de políticas sociais continua sendo necessária e justa, mas não é mais a única estratégia dos movimentos. Pensa-se em um caminho complementar, de solução autônoma dos problemas por parte da sociedade, já que o Estado se

1 Dicionário de Ciências Sociais, 1987

2 M. Castells cunhou, nos anos 70, a expressão "movimentos sociais urbanos" para se referir aos movimentos de reivindicações coletivas a partir das contradições que se situam fora da área imediata da produção - aquelas que ocorrem no nível do consumo coletivo. Essas contradições propriamente urbanas estão relacionadas: a) à organização social do espaço, com a grande concentração de pessoas sem recurso algum nas grandes cidades e a inexistência de mecanismos econômicos para sua reprodução e de mecanismos sociais para o seu controle; b) à produção, distribuição e gestão dos meios de consumo coletivo (habitação, transporte, saúde, educação, equipamentos coletivos, etc) (Cf. Castells, M., 1974)

3 Senna Filho, A.R., 1994 
mostra inoperante ou ausente. O fortalecimento da sociedade civil aparece como alternativa mais aberta aos problemas sociais e à reelaboração de novas formas de relação entre sociedade e Estado. É necessário levar em conta a visão das pessoas e coletividades sobre os seus problemas, e as soluções que constróem. ${ }^{1}$

Trata-se, nessa nova abordagem dos movimentos, de visualizar espaços de mobilização e novas formas de movimentar as ações coletivas, e entender seus significados políticos e culturais. ${ }^{2}$

A inovação mais recente nos movimentos encontra-se no surgimento de práticas políticas articulatórias das ações localizadas, de redes de movimentos (nethorks) e na busca de metodologias que permitam entendê-las. Trata-se também de perceber as interconexões entre o local (comunitário) e o gdbal (supranacional, transnacional), o que gera uma cultura política que tem levado os movimentos e suas lideranças,

(...)a alargarem suas visão cotidiana original e a descartarem os remanescentes de seu sectarismo restritivo, se ramificarem em várias direções e juntarem forças em frentes unificadas de ação... Trata-se de passar da análise de organizações sociais específicas, fragmentadas, para a compreensão do movimento real que ocorre na articulação dessas organizações, nas redes de movimentos. ${ }^{3}$

O enfoque das redes de movimentos deixa transparecer a evidência de que as redes de movimentos sociais são tributárias de dinâmicas sociais híbridas. Sua existência e funcionalidade fazem transparecer uma hibridação entre o commitáiioe o assoiativo A dinâmica associativa está fundada no recurso da estruturação organizacional da ação (como nas organizações não-governamentais), enquanto o comunitário está vivo na mensagem religiosa que as igrejas, grupos e entidades difundem.

Essas constatações têm demandado uma visão reticular das mobilizações dos movimentos sociais, suas lógicas sociais plurifuncionais, com dimensões ao mesmo tempo integradoras, utilitárias e contestatórias, que fazem aparecer a multiplicidade de funções que essas redes desenvolvem na condução das suas estratégias.

Redes de movimentos é assim um construto analítico-prático que favorece a visão sobre a possibilidade de integração de iniciativas locais de indivíduos, organizações e grupos, e seu potencial de leitura e transformação das condições de vida da

1 Valla, V. V., 1998

2 Scherer-Warren, I., 1993. A autora, ao se referir às novas abordagens dos movimentos sociais, lembra que as modificações nas abordagens não são o mero fruto do repensar teórico. "Há transformações nas realidades internas dos países latino-americanos e externas com repercussões transnacionais sobre a prática efetiva dos movimentos sociais. Internamente, destacam-se os movimentos de democratização política e de reformas institucionais. Externamente, as transformações no socialismo real trazem perplexidades em relação às utopias dos movimentos populares na América Latina.. As modificações históricas conduzem ao repensar das teorias." (Cf. p. 21-22, grifos nossos)

3 Op. cit., p. 22 
população, em contexto político e econômico diverso daquele no qual se originaram os movimentos sociais mais formais ou institucionalizados.

\section{Reeles ecampos sodais}

As redes de movimentos se articulam de maneira a retraduzir as situações que os indivíduos buscam melhorar, gerando pontos de mobilização e organização onde as questões são apresentadas e discutidas a partir de diferentes pontos de vista, de acordo com a posição de cada agente no espaço social.

Dois perfis de agentes compõem em geral as redes assim formadas: a) os agentes internos e b) os agentes externos. Os primeiros são os pertencentes à comunidade (ou população, ou camadas populares) seja como lideranças, representantes de associações e entidades, membros de grupos comunitários. Os segundos são os mediadores, ou assessores, ou educadores populares originários de instituições acadêmicas, igrejas, organizações não-governamentais, orgãos públicos, partidos políticos, entre outras entidades.

A fraca hierarquização e a ausência de especialização de papéis nas redes levam esses agentes (internos e externos) a confrontarem de forma constante seus discursos, visões e experiências adquiridos em seus respectivos espaços sociais de inserção. Essas características das redes de movimentos levou ao emprego do conceito de campo de forma complementar ao de rede, de maneira a não perder de vista o perfil de cada agente no funcionamento das redes e as formas discursivas e cognitivas próprias aos seus campos de origem e/ou de pertencimento.

Os conceitos de rede e campo têm proximidades analíticas, pois ambos referemse ao espaço social das relações entre indivíduos movidos por objetivos comuns. ${ }^{1}$ Entretanto, enquanto o primeiro refere-se aos ambientes informais de interações fracamente institucionalizados, o segundo é aplicado ao estudo das esferas institucionais formais ou "consagradas" do universo social como a religião, a educação, a economia, a política, dentre outras.

1 O conceito de campó central na sociologia de P. Bourdieu e pode ser aproximado aos conceitos de reelee configuraçãoem N. Elias. P. Bourdieu assim se refere ao conceito de campo : "Eu poderia, deformando a célebre fórmula de Hegel, dizer que o real é relacional: o que existe no mundo social são relações - não as interações ou os elos intersubjetivos entre os agentes, mas as relações objetivas que existem "independentemente das consciências ou das vontades individuais, como dizia Marx. Em termos analíticos, um campo pode ser definido como uma rede, ou uma configuração de relações objetivas entre as posições. Estas posições são definidas objetivamente na sua existência e nas determinações que elas impõem aos seus ocupantes, agentes ou instituições, pela sua situação (situ) atual e potencial na estrutura de distribuição das diferentes espécies de poder (ou de capital) cuja possessão comanda o acesso aos benefícios específicos que estão em jogo no campo, e, ao mesmo tempo, pelas suas relações objetivas com as outras posições ( dominação, subordinação, homologia, etc). Nas sociedades altamente diferenciadas, o cosmos social é constituído pelo conjunto desses microcosmos relativamente autônomos, espaços de relações objetivas que são o lugar de uma lógica e de uma necessidade específicas e irredutíveis àquelas que regem os outros campos." (Bourdieu, P.; Wacquant, L. J. D., 1992, grifos nossos) 
Os campos são formas de estruturação do espaço social e designam, de maneira analiticamente mais maleável, aquilo que a teoria social conhece classicamente como instituição e/ou organização. Os campos representam as situações institucionalizadas onde os atores desempenham seus papéis e desenvolvem suas ações regidos por regras válidas para cada campo, especificamente. A possibilidade de cada ator social participar de um ou outro campo depende de sua posição no espaço social, a qual está associada à aquisição e posse de determinados capitais -sociais, culturais, pedagógicos, informacionais- distribuídos socialmente, cujas instâncias básicas de distribuição são a família e a escola.

Os diferentes capitais são adquiridos e exteriorizados através dos habitusdos atores em diferentes situações sociais, os quais funcionam como gabaritos ou programas de percepção, representação e expressão. Os habitusencontram-se relacionados aos campos de pertencimento dos atores sociais, exigindo destes últimos certos inestimentos simbólicos pelos quais se garante a "crença" nos princípios de cada campo, a consciência de pertencimento e se trabalha pela sua consolidação e autonomia em relação a outros campos. ${ }^{1}$

Os agentes internos e externos das redes de movimentos sociais possuem habitus próprios oriundos dos seus campos: o comunitário, o associativo, o acadêmico, o político, o religioso, das ONGs. Os conceitos de campoe redefuncionam como operadores analíticos e empíricos para a identificação das matrizes discursivas e cognitivas dos agentes, dos seus canais de comunicação, dos processos de transferência das informações e do conjunto de emissores e receptores e seus elos nas redes.

\section{Conheimento, Infomarãa, Comunicação}

A visão corrente sobre os três conceitos centrais do modelo Interpretativo de Análise aponta para a sua relação automática, ou seja, a de que uma informação relevante ou correta é aquela capaz de gerar um conhecimento sustentado, que por sua vez supõe a sua comunicação transparente, gerando novas informações e realimentando o processo cíclico e em cadeia.

A concepção que sustenta essa visão é a de que a falta de informações corretas dificulta às pessoas o acesso à realidade, ou seja ao "como e porque as coisas acontecem" e que a retenção de informações pelas fontes geradoras - cientistas, instituições, mídia, etc, impede a partilha democrática do saber. ${ }^{2}$

Como ponto de partida para o estudo das redes de conhecimentos que se formam nos elos entre os agentes internos e externos aos movimentos sociais, é neces-

1 Bourdieu, P., 1980

2 As concepções e críticas sobre a visão mecânica e eficiente da tríade conhecimento/informação/comunicação empregadas nesta parte encontram-se apoiadas nas reflexões de L. Sfez. (Cf. Sfez, L., 1994; 1996) 
sário recuperar alguns elementos que mostram as dificuldades inerentes à ligação espontânea que se costuma estabelecer entre os três termos.

Conhecimento e Informação são conceitos interligados pela sua natureza comum $-\mathrm{O}$ ato de obter e dar significado cultural (compartilhado) ao mundo, mas não são processos idênticos, ou que se confundem. E funcionam em níveis distintos. $\mathrm{O}$ processo de conhecimento supõe estruturação e depuração de informações: seleção da informação relevante; triagem e eliminação da informação supérflua , o que garante a "eficácia da memória", uma vez que não se pode reter todas as informações disponíveis.

Por outro lado, a informação amplamente disseminada ou "democrática" não gera conhecimentos iguais. A comunicação é um processo no qual estão envolvidos o emissor (que cria a mensagem), o canal (onde a mensagem sofre modificações ou ruídos) e o receptor (que interpreta a mensagem).

No universo empírico estudado - as redes de movimentos sociais da Leopoldina as ações dos agentes estão baseadas numa concepção de "construção compartilhada do conhecimento" onde se intercruzam três eixos de saber:

a) o conhecimento produzido e controlado pelos órgãos oficiais a respeito das condições de vida da população;

b) o conhecimento acadêmico ou perspectivas de análise teóricas e metodológicas voltadas à compreensão dos processos de produção de desigualdade e miséria;

c) o conhecimento dos sujeitos que vivem concretamente as condições de vida que geram os problemas e situações que são objeto das ações dos agentes nos movimentos. ${ }^{1}$

A produção compartilhada entre agentes internos e externos dos movimentos tem uma dimensão de "apropriação do conhecimento" do outro, em procedimentos comunicacionais e informacionais circulares de adequação e orientação das diferentes matrizes perceptivas e cognitivas para a resolução das suas questões teóricopráticas. $^{2}$

\section{O TexerroConheimento}

A idéia de teceiroconheimentovem sendo elaborada para descrever e interpretar os processos de construção compartilhada e de apropriação dos conhecimentos como

1 "Construção compartilhada do conhecimento" é uma formulação encontrada em documentos, artigos, teses, cursos, reuniões. É empregada pelos especialistas do CEPEL e do ELOS/ENSP/FIOCRUZ para designar um modo próprio e alternativo de produção do conhecimento, diferente dos padrões elitistas da academia. A produção compartilhada do conhecimento serve à academia como forma de revisar suas formas de ensinar, aprender, pesquisar. Para os movimentos populares como meio de valorização dos conhecimentos adquiridos na experiência - o conhecimento prático - e sua capacidade de intervenção no dado da realidade, para transformá-lo. (Cf. Cunha, M. B.; Oliveira, R. M., 1997, p. 8 e segs.) 
uma modalidade de saber produzida pela união do conhecimento especializado (dos pesquisadores, técnicos, especialistas) com o conhecimento popular.

Essa união fugiria à idéia de superioridade do conhecimento formal, valorizando também como rica e importante a sabedoria popular, baseada em experiências e práticas vividas. Para que esse encontro/confronto se realize, sem que o conhecimento popular seja encoberto e desvalorizado diante do científico, é necessária uma nova forma de integração entre essas duas visões de mundo distintas e complementares. É preciso reconhecer o valor do conhecimento popular, compreendendo-se suas lógicas de produção e seus contextos específicos de uso. E, tanto quanto, gerar uma nova forma de encarar o conhecimento científico, não sendo este visto como saber superior e único. Essa aliança só se constrói na medida em que as partes reconheçam a desigualdade de suas posições, especialmente quanto ao saber, tomando esta desigualdade como ponto de partida para a construção de um conhecimento novo. ${ }^{1}$

2 A discussão propriamente acadêmica a respeito das formas compartilhadas de construção ou apropriação dos conhecimentos produzidos tem como eixo, no caso estudado, a situação historicamente problemática da saúde pública no país - as políticas públicas equivocadas, o atendimento precário dos serviços de saúde. Para aqueles que se alinham ao trabalho da "Educação Popular e Saúde", com a crise econômica mundial e a retração das políticas sociais do Estado, é necessário pensar novas formas de melhorar as condições de vida e saúde da população pobre, valorizando suas formas alternativas de pensar e atuar sobre o seu quadro de vida. Tanto para os que estão mais próximos da população carente - os profissionais dos serviços de saúde - quanto para professores, pesquisadores, alunos, representantes e lideranças das comunidades é oportuno lembrar que "A história nunca começa com o contato dos profissionais dos serviços com as suas clientelas. A história é anterior: há um passado que ainda vive, em sua virtualidade, no presente e está referido às experiências acumuladas em uma gama amplamente diversificada de alternativas, bem como às lutas moleculares ou coletivas que enraízam formas de pensar e agir." (Cf. Valla, V. V.,1998, p.10; Valla, V. V., Stotz, E. N., 1993)

1 Nas discussões entre pesquisadores, estudantes, técnicos dos serviços públicos e representantes das organizações populares da Leopoldina uma questão que se discute com freqüência é a do descompasso entre o conhecimento adquirido na academia e as questões vividas pela população: "Se, de um lado, os representantes de organizações populares vinham buscando informações que não possuiam, os profissionais, por sua vez, demonstravam uma preocupação semelhante. Na realidade, suas formações universitárias revelam lacunas justamente nas áreas de conhecimentos que se relacionam com os problemas agudos da população trabalhadora (problemas de aprendizagem de crianças das classes populares, vigilância epidemiológica e sanitária, saneamento básico, por exemplo). Nesse sentido, a ótica elitista dos currículos universitários faz com que assuntos tratados nas universidades freqüentemente passem ao largo de questões de educação e saúde ligadas às necessidades da população. (...) o que estava-se gestando nesse processo de investigação científica "do ponto de vista popular" era a percepção intuitiva dos pesquisadores, profissionais e população de que a reivindicação dos serviços de educação e saúde poderia ter até o lastro de uma discussão política, mas carecia freqüentemente de informações técnicas. Na realidade o que estava nascendo era um processo de capacitação mútua envolvendo pesquisadores, profissionais e organizações populares." (Cf. Valla, V. V., 1993, p. 91, grifos nossos). Essa concepção de "construção coletiva do conhecimento" que fortalece as ações dos agentes nos movimentos não depende de um simples "repasse" de informações entre as partes, numa ótica de "carência informacional". O que leva a essa construção compartilhada é a estruturação e o fortalecimento das redes sociais de apoio já existentes nas comunidades. "Rede essa que possibilita a ampliação e o fortalecimento dos sujeitos, à medida que potencializa o uso das distintas informações. A ação transformadora dos sujeitos 
O teceirocanheimentoconstitui-se em redor de temas e problemas que em dados momentos são adotados como relevantes pelos agentes como projetos de vida locais, sejam eles lutar pela melhoria dos serviços de saúde ou das escolas, pela criação e/ou manutenção de um espaço verde ou de lazer, ou na organização de atividades recreativas e culturais que reforcem os elos e tradições da comunidade. Nessas situações são empregados diferentes recursos e meios de comunicação e informação (documentos oficiais, notícias e matérias veiculadas na mídia, relatórios técnicos e orçamentários de órgãos públicos, as rádios e jornais comunitários). Ao mesmo tempo em que se ativam as redes de contato e de apoio por diferentes meios, principalmente informais, onde o exercício da comunicação e da linguagem é fator básico para o esclarecimento de questões e a tomada de decisões.

Nesses enclaves que podem ter duração de meses, anos ou de toda uma vida, os agentes exercitam suas potencialidades individuais e coletivas e mobilizam os recursos políticos, cognitivos, simbólicos que são capazes de reunir e intercambiar. ${ }^{1}$ Esses são os espaços práticos e simbólicos de análise do plano cognitivo-informacional das redes sociais -as reeles de conheimetos- onde são tecidas as relações contraditórias de constituição do texceroconheimento

Para estudar as redes de "construção compartilhada do conhecimento" e seu potencial para a geração de novas práticas e políticas de gestão social dos conhecimentos é relevante considerar que o teceiro conheimento não é um produto ou conhecimento diferente daqueles que lhe deram expressão. Nem mesmo é uma "nova informação". É um construto de ordem prática e simbólica que permite aos agentes uma destreza para lidar com questões práticas do cotidiano e, muito mais, um meio de valorização e fortalecimento dos elos de apoio social e de suas capacidades inventivas. Também é forma de construção de uma "nova epistemologia" pelo intercruzamento de saberes e práticas, que revela o lugar ético-político do conhecimento científico. $^{2}$

se dá então, muito mais pela ampliação e fortalecimento das relações do que necessariamente pela construção de uma nova informação. Quando os sujeitos, mesmo informados, não se sentem apoiados, procuram outros espaços onde estão colocadas outras oportunidades de apoio e invenção." (Cf. Oliveira, M. R., 1998, p. 76, grifos nossos)

1 Um exemplo desses embates é a luta histórica da população da região pelo abastecimento de água, com poucas soluções favoráveis para as comunidades. A busca de soluções alternativas para o problema fêz com que as pessoas das localidades desenvolvessem um conhecimento técnico da rede de distribuição de água, gerando inovações para abastecer os pontos mais elevados das favelas, p. ex. ( Essas questões foram objeto de estudo de dissertação de mestrado na ENSP/FIOCRUZ. Ver Oliveira, R. M., 1993) Outro exemplo é a luta pela reabertura do Posto de Saúde da Vila do João, que era mantido pela UFRJ e que veio a ser fechado alguns anos depois por motivo alegado de problemas de violência na região gerado pelo tráfico de drogas. Um grupo de mulheres lidera desde então um movimento pela reabertura do Posto, criando recentemente uma ONG - Grupo de Amigos da Vila do João e Adjacências (GAVJA) que vem gerenciando recursos repassados pelo poder público para a manutenção do Posto de Saúde, que fora desativado pela universidade com toda a aparelhagem médica e odontológica cuidada e guardada durante anos pelas mulheres da Vila do João. 
Redes e configurações de comunicação e informação: construíndo um modelo... 89

\section{Linguagmmanativa elinguagminfomadional}

Nesse quadro a linguagmadquire fundamental importância para que se estabeleça uma comunicação. Cada agente, no cotidiano das práticas e vivências nas redes de mobilização de recursos materiais e simbólicos, tem de levar em conta as experiências e perspectivas dos outros. Cria-se uma interação discursiva e prática, que traz para

B. S. Santos ao tratar da nova epistemologia fundada no contexto da "ciência pós-moderna"em processo de construção, lembra que “... aslèsdaciêniamodemas̃aumtipodecausafơmal o como funciona dasccisas, emderimentodequal o agente ou qual o fim das coisas". É por essa via da ciência normal que o conhecimento científico tem se afastado do conhecimento de senso comum, pois " .... enquanto no senso comum, e portanto no conhecimento prático em que ele se traduz, a causa e a intenção convivem sem problemas, na ciência a determinação da causa formal obtém-se com a expulsão da intenção". O novo paradigma científico expresso pela ciência pós-moderna tende, ao contrário, a valorizar o diálogo entre as várias formas de conhecimento. Lembrando o conceito de "agir comunicacional" desenvolvido por J. Habermas, o autor mostra que "ommdbécommicadianal" e por isso a lógica existencial da ciência pós-moderna é de promover a "situação comunicativa”. Nesta, segundo o autor, confluem sentidos e constelações de sentidos gerados das práticas locais e dos percursos individuais, comunitários, sociais e planetários, operados por "comunidades interpretativas" compostas por agentes e subjetividades diversas, que não produzem um "amálgama de sentidos" (que não seria sentido, mas ruído), mas antes interações e "intertextualidades" organizadas em torno de projetos locais de conhecimento indiviso". (Cf. Santos, B. S., 1995, p. 16;45)

$\mathrm{H}$. Wainwright desenvolve a idéia de que os novos movimentos sociais vêm historicamente colocando em prática uma nova compreensão do conhecimento: "A novacompręsãodadênaiaqueaprática[ dos moimentos] indicavêaexperiêniaeateena, osentimetoeointdeto, numardaçãodereiproidade eareiprocidade éumproesso mais queummmentofixodeveificaçãoaufalsificaşão'. A autora mostra que um dos efeitos pouco visíveis até hoje das revoltas estudantis do ano de 1968 foi a geração de novas idéias e práticas na produção, organização e caráter do conhecimento. Outros movimentos sociais em momentos posteriores questionaram as formas de conhecimento existentes de maneira mais consciente: o movimento feminista e o movimento ecológico, p. ex. Dessas críticas assim elaboradas pelos movimentos sociais surgiram a inovação e a afirmação prática de alternativas, especialmente a afirmação da validade do conhecimento experimental [ou prático] “.... não simplesmente como fonte de instâncias empíricas, ou falsificações, de uma lei geral, mas como pistas, sinalizações e stimuli para aprofundar a compreensão e a inovação teórica. Aliada a isso havia uma tentativa de desmistificar o conhecimento teórico e defender uma abordagem pluralista ao seu desenvolvimento.(...) As diferentes abordagens ao caráter e organização social do conhecimento faziam parte do que tornava esses movimentos 'novos'. Diversas abordagens distintas e inovadoras do conhecimento surgem com esses movimentos e"... ilustram como eles têm uma compreensão mais rica de formas não codificadas de conhecimento e seu potencial para ser compartilhado e tornado público, compreensão capaz de fornecer uma base para tipos particulares de desafio ao Estado de engenharia social“. Tais abordagens alternativas do conhecimento elaboradas pelos novos movimentos refletem o desafio implícito à compreensão positivista da ciência , enfatizando em diferentes graus "... a importância do conhecimento tácito, do caráter de desenvolvimento e falibilidade do conhecimento, de sentimentos e emoções servindo de estímulos ao conhecimento (em vez de serem considerados atributos humanos de menor importância), da pesquisa de estruturas subjacentes. Simultaneamente, estes movimentos compartilharam uma visão de si mesmos como agentes de transformação". No seu modus operandi esses novos movimentos “.... tentaram organizar seus próprios processos de elaboração de políticas de um modo que explicitamente levasse em conta o conhecimento diário e as habilidades de seus participantes. Assim, suas organizações baseiam-se em uma autonomia e diversidade de iniciativas e debates que é comum a projetos influenciados por quaisquer dos movimentos: workshops, rodízio nas posições de liderança e a criação de redes horizontais refletem essa preocupação de estabelecer formas de conhecimento fora da noção ortodoxa da ciência.”. (Cf. Wainwright, H., 1998, p. 28; p. 57-75) 
o campo do popular a possibilidade de entendimento do conhecimento das técnicas e das ciências sob duas óticas distintas: a) pelo seu teor prático-informacional, ou seja, como "benesse" ou produto de consumo para dar curso às ações e decisões; b) pelo seu teor simbólico, como formador de dignidade e valoração humanas e da consciência de pertencer a uma "sociedade da informação".

A interação lingüística assim estabelecida traz ainda para o campo do saber científico a possibilidade de apreender e anexar o saber narrativo da experiência de vida, fonte cultural de todo conhecimento autêntico. Neste plano se organizam as reedesde sentidose se revelam as subjetividades, tempos, espaços e memórias próprios de cada um dos agentes, em uma dimensão de apropriação dos conhecimentos de uns e de outros para a transformação social. É esse movimento que denominamos de "intertextualidade".

Cada linguagem - enquanto modalidade prática e discursiva- possui suas especificidades históricas e sociais e as mudanças possíveis na ordem do conhecimento passam pelas pragmáticas comunicacionais nos ambientes do mundo vivido onde se exercitam as trocas, estranhamentos e conflitos entre diferentes formas discursivas - as "disputas simbólicas".

A linguagem ou discurso narrativo é por excelência o espaço de transmissão da sabedoria popular. Seus relatos realizam a transmissão e perpetuação das experiências vividas. A narrativa está dessa maneira associada à tradição oral, às múltiplas formas de se contar uma mesma história que traz em si o fantástico, o miraculoso, o fascínio do distante, a relação com o tempo da vida e o mistério da morte. Quem narra sempre transmite um ensinamento, um conselho de utilidade prática, que são parte da sabedoria adquirida através do tempo, ou da "viagem que faz conhecer o mundo" em suas distâncias temporais e espaciais. ${ }^{1}$

A linguagem informacional (ou lógico-racional, ou científica) tem por característica a necessidade de ser comprovada, plausível, verificável. Tem teor utilitário e produtivo.

No entanto, ainda que encoberta ou "colonizada" pela ciência e pela informação, a narrativa continua a existir e está presente em modos de viver e fazer populares e na transmissão de saberes vividos de pessoa para pessoa. Esta sabedoria se reflete

1 W. Benjamin associou o declínio da narrativa como forma principal de transmissão dos saberes a duas ordens de fatores; a) o advento do romance, que prenuncia o homem isolado, individualista, ao contrário do narrador, que pressupõe o envolvimento com a coletividade; b) à consolidação de uma nova forma de comunicação - a informação - associada à própria consolidação da burguesia e seu instrumento maior de comunicação e poder - a imprensa. O saber narrado, que vem do longe territorial ou da memória, dispunha de uma autoridade válida mesmo que não fosse controlável pela experiência. Já a informação é causal, lógico-racional e aspira a uma verificação. Enquanto os relatos recorrem ao miraculoso, é indispensável que a informação seja plausível. Nos anos $30 \mathrm{~W}$. Benjamin afirmava que nesse sentido a informação é incompatível com a narrativa: "Se a arte de narrar é hoje rara, a informação é decisivamente responsável por esse declínio”. (Benjamin, W., 1993, p. 197-221) 
nos usos práticos feitos dos produtos da ciência que refletem criatividade e inventividade, e mesmo na forma de habitar a cidade - buscando espaços de identificação subjetiva e emocional e criando modos particulares de se locomover pelos caminhos do urbano.

Essas propriedades das diferentes formas discursivas - a narrativa e a informacional- são elementos importantes para uma análise dos papéis e posições dos agentes nas redes de movimentos e nos processos de produção de sentidos. No entanto não se trata de identificar, qualificar ou atribuir valores a cada uma dessas expressões discursivas. Se ambas se comunicam em vista de objetivos práticos e simbólicos comuns, importa mais considerar seus fins práticos de transformação do que revelar seus traçados essenciais ou universais.

O mapeamento reticular e relacional desses "núcleos de energia social" tem por objetivo interpretá-los como espaços de negociação e produção de sentidos ou como configurações, sempre provisórias, de comunicação e informação.

\section{ALGUMAS CONSIDERAÇÕES FINAIS}

O processo investigativo vem sendo realizado com o objetivo de estudar as práticas e políticas de conhecimento, da comunicação e da informação no chamado Terceiro Setor, entendendo-o como uma vasta rede de contatos entre diferentes agentes e campos sociais com vistas à transformação social. Ao longo do processo foi elaborado o modelo interpretativo de análise, combase nos pressupostos teóricos iniciais e no recorte empírico da pesquisa.

Os instrumentos metodológicos que vêm sendo empregados - a metodologia de análise de redes sociais e os métodos qualitativos - permitem representar a configuração das redes de movimentos nos seus aspectos estruturais e dinâmicos, as posições e elos dos agentes, seus modos de comunicação. E, por outro lado, mostra os diferentes papéis representados pelos integrantes das redes, e como investem recursos dialógicos, cognitivos e simbólicos para o fortalecimento dos elos, as tomadas de decisões e a direção do próprio movimento.

O emprego do modelo interpretativo tem evidenciado as formas de articulação entre os conhecimento prático e científico, com potencial para a formulação de novos parâmetros de produção e gestâo do conhecimento na sociedade, além daqueles controlados pelo Estado e pelo mercado.

Um dos desdobramentos já previstos na fundamentação conceitual do modelo é o estudo da teia de sentidos construída a partir dos elos sociais e combinações cognitivas, que expressam o modo articulado de ser do terceiro conhecimento.

Do terceiro conhecimento faz parte o conhecimento prático, forma compartilhada de produção de sentidos para a ação sobre o mundo vivido da população privada do acesso e usufruto dos bens e serviços sociais. 
O conhecimento prático é produzido pelos diferentes fazeres, trabalhos e atividades dos agentes sociais, portanto é parte integrante do conhecimento como um todo, é uma das formas de conhecimento modernas. Constitui o senso prático (bourdieu, P.1980; 1994) que orienta a ação dos agentes sociais. Pode ser a ação do hábito ou da rotina, a reprodução das instituições ou dos modos de fazer. Pode ainda tornar-se, em diferentes graus, ação de transformação ou criação. (wainwright, 1998, p.14)

A noção de configurações de comunicação e informação representa as conexões entre os diferentes fragmentos do conhecimento prático, e entre este último e outras formas de conhecimento histórico e teórico, para construir visão ampla sobre o espaço, o tempo e as práticas e estruturas sociais, assim como organizar redes e alternativas a serem postas em andamento para a democratização das próprias formas de produção e organização do conhecimento na sociedade.

\section{BIBLIOGRAFIA}

BARNES, J. A. Social newarks (An Addison-Wesley Module in Anthropology) Module 26, 1972, p. 1-29.

BARrETO, Aldo de Albuquerque. A questão da informação. SãoPauloemPes petiva, R. daFundaçãoSEADE, São Paulo, v. 8, n. 4, p. 3-8, out./dez. 1994.

BENJAMIN, Walter. Magjaeténica, arteepdítica; ensaiossdbreliteraturaehistónada aultura 5. ed. São Paulo : Brasiliense, 1993. (Obras escolhidas; v. 1)

BOTT, Elizabeth. Famíliaerøescial. Tradução de Mário Guerreiro. 2. ed. Rio de Janeiro : F. Alves, 1976.

BOURDIEU, Pierre. Lesenspratique Paris : Les Éditions de Minuit, 1980.

- - -. (Coord.) A miséria do mundo. 2. ed. Petróppolis, RJ : Vozes, 1997.

- - -.. Raisons pratiques; sur la theórique de l'action. Paris: Sevil, 1994.

---, W ACQUANT, Loïc J. D. Réponses; pour una antropologie réflexive. Paris: Sevil, 1992.

CASTELlS, M. La arestiónumbana Buenos Aires : Siglo XXI, 1974.

COLONOMOS, Ariel (org.) Socidogiedesréseux transnationaux; commmautés, entrepises \&individus: lien social et système international. Paris : l'Harmattan, 1995.

CunHA, Marize B., Oliveira, Rosely M. Construindo indicadores sobre as condições de vida nos bairros e comunidades da região da Leopoldina. Rio de Janeiro: CEPEL; ELOS/ENSP/FIOCRUZ, 1997.

DAGNINO, Evelina (Org.) Os anos 90 : política e sociedade no Brasil. São Paulo : Brasiliense, 1994.

DEGENNE, Alain, Forsé, Michel. Lesrésux sociaux; uneanalysestructuraleenso adoge Paris : Armand Colin, 1994. 
DERVIN, Brenda. Information/Democracy : an examination of underlying assumption. Jaumal of theAmerican SocieyforInfomationSaience v. 45, n. 6, p. 369-387, 1994.

DiCIONÁRIO de Ciências Sociais. $2^{a}$ ed. Rio de Janeiro: Ed. Fundação Getúlio Vargas, 1987.

ELIAS, Norbert. Qúet-cequela Socidogje? Paris : Ed. de l'Aube, 1991.

- - - A socieladedosindiúduos Rio de Janeiro : Zahar, 1994.

EMIRBAYER, Mustafa, Goodwin, Jeff. Network analysis, culture and the problem of agency. AmmicanJoumal of Socidogy, v. 99, n. 6, p. 1411-1454, May 1994.

GEERTZ, Clifford. O saberloal : novos ensaios em antropologia interpretativa. Petrópolis, RJ : Vozes, 1997.

HEINICH, Nathalie. LasoidojedeNorbatElias Paris : La Découverte, 1997.

LANDIM, Leilah. ParaalémdbMeradbedbEstadb?filantropiaedidadanianoBrasil Rio de Janeiro : ISER, 1993. (Série Textos de Pesquisa)

LATOUR, Bruno. Ces réseaux que la raison ignore: laboratoires, bibliothèques, collections. In: Baratin, Marc, Jacob, Christian. Lepandirdesbiblicthèquesen Occidant Paris : Albin-Michel, 1995. p. 23-46.

LE COADIC, Yves François A Ciênia da Informaçãa Brasília, DF : Briquet de Lemos, 1996.

- - - Usages \& usagers del'infommation Paris : ADBS/Anthan, 1997.

LÉVY, Pierre. A inteligêniađeleiva:por uma antropologia do ciberespaço. São Paulo: Edições Loyola, 1998.

---.. Astemdogasdainteligênia: o futuro do pensamento na era da informática. Rio de Janeiro : Ed. 34, 1993.

- - -.. A virtualização db texto 1998. In: O VIRTUAL. Seminários realizados pelo autor, organizados pelo Núcleo de Estudos da Imagem, ECO/UFRJ, 18-22 maio 1998.

---., AUTHIER, Michel. Asárvoresdeconheimento São Paulo : Escuta, 1995.

MARTELETO, Regina Maria. “Lugares de signos” e contextos de informação; a biblioteca como metáfora dos conhecimentos modernos. R. deBiblidteron deBrasilia, v. 20, n. 2, p. 241-246, 1996.

MICELI, Sérgio. Norbert Elias e a questão da determinação. In: Waizbort, Leopoldo (Org.) DossiêNabat Elias São Paulo : EDUSP, 1999.

OlIVEIRA, Rosely Magalhães. A dengue no Rio de Janeiro : repensando a participação popular em saúde. CademosdeSaúdePúllica Participação popular e controle de endemias. Rio de Janeiro, v. 14, p. 69-78, 1998. Suplemento 2.

ORLANDI, Eni Puccinelli. Interpreaçãa Autoria, leituraefétosdbtrabalhosimbóiœa Petrópolis, RJ : Vozes, 1996. 
PAIM, Isis, Nehmy, Rosa $M^{a}$ Q. Questões sobra a avaliação da informação : uma abordagem inspirada em Giddens. PespeetivasemCiêniadaInfomaçãa Belo Horizonte, v. 3, n. 1, p. 81-95, jul./dez. 1998.

SANTOS, Boaventura de Souza. Umdisarsosdreasciênias 7. ed. Porto [Portugal] : Afrontamento, 1995.

-- -.. PdamãodeAlice, oscial eopdíticonapósmodamidade São Paulo : Cortez, 1995.

SCHERER-WARREN. Ilse. Reeks de moimentos soiais São Paulo : Edições Loyola, 1993.

SENNA FILHO, Arthur Ribeiro de. Organizações Não-Governamentais de assessoria popular, novos movimentos sociais, Estado e democracia. R. ServiçoSocial eSociedade, n. 45, p. 43-65, 1994.

SFEZ, Lucien. Crítica da comunicação. São Paulo: Ed. Loyola, 1994.

---. Informação, saber e comunicação. INFORMARE - Cad Prog PósGrad Ci. Inf, Rio de Janeiro, v. 2, n. 1, p. 5-13, jan./jun. 1996.

TORO, José. B. O papel do Terceiro Setor em sociedades de baixa participação (quatro teses para discussão). In: Ioschie, Evelyn B. $3^{\circ}$ Star, desendudimettoscaial sustentado São Paulo: Paz e Terra, 1997. p. 35-40.

VALLA, Victor V. A construção desigual do conhecimento e o controle social dos serviços públicos de educação e saúde. In: Valla, Victor V., stotz, Eduardo N. Partiajpaçãoppular, eduraçãoesaúde: teoria e prática. Rio de Janeiro : Relume-Dumará, 1993. p. 89-100

- - -.. Sobre participação popular : uma questão de perspectiva. Cademos de SaúdePública, suplemento 2, Rio de Janeiro, v. 14, p. 7-18, 1998.

- - -., STOTZ, Eduardo N. Participação popular, educação e saúde: teoria e prática. Rio de Janeiro: Relume-Dumará, 1993

WAINWRIGHT, Hilary. Uma resposta aonediberalismo: argumentos para uma nova esquerda. Rio de Janeiro : Jorge Zahar, 1998.

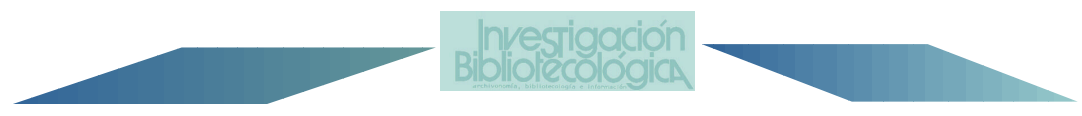

